\title{
Cellular death of two non-Saccharomyces wine-related yeasts during mixed fermentations with Saccharomyces cerevisiae
}

\author{
F. Pérez-Nevado ${ }^{b, 1}$, H. Albergaria ${ }^{a, 1}$, T. $\operatorname{Hogg}^{c}$, F. Girio $^{a, *}$ \\ ${ }^{a}$ Unidade de Fisiologia Microbiana e Bioprocessos, Departamento Biotecnologia, Instituto Nacional de Engenharia Tecnologia e Inovação, \\ Estrada do Paço do Lumiar, 22, 1649-038 Lisboa, Portugal \\ b Área de Nutrición y Bromatología, Departamento de Zootecnia, Univ. de Extremadura, Badajoz, Spain \\ ${ }^{\mathrm{c}}$ Escola Superior de Biotecnologia, Universidade Católica Portuguesa, Rua Dr. António Bernardino de Almeida, 4200-072 Porto, Portugal
}

Keywords: Non-Saccharomyces wine yeasts; Mixed cultures; Cellular death; Toxic compounds; Yeast-yeast interactions

\begin{abstract}
The early death of two non-Saccharomyces wine strains (H. guilliermondii and H. uvarum) during mixed fermentations with S. cerevisiae was studied under enological growth conditions. Several microvinifications were performed in synthetic grape juice, either with single nonSaccharomyces or with mixed S. cerevisiae/non-Saccharomyces inocula. In all mixed cultures, non-Saccharomyces yeasts grew together with $S$. cerevisiae during the first 1-3 days (depending on the initial inoculum concentration) and then, suddenly, non-Saccharomyces cells began to die off, regardless of the ethanol concentrations present. Conversely, in both non-Saccharomyces single cultures the number of viable cells remained high (ranging $10^{7}-10^{8} \mathrm{CFU} \mathrm{ml}^{-1}$ ) even when cultures reached significant ethanol concentrations (up to $60-70 \mathrm{~g}^{-1}$ ). Thus, at least for these yeast strains, it seems that ethanol is not the main death-inducing factor. Furthermore, mixed cultures performed with different $S$. cerevisiael H. guilliermondii inoculum ratios $(3: 1 ; 1: 2 ; 1: 10 ; 1: 100)$ revealed that $H$. guilliermondii death increases for higher inoculum ratios. In order to investigate if the nature of the yeast-yeast interaction was related or not with a cell-cell contact-mediated mechanism, cell-free supernatants obtained from 3 and 6 day-old mixed cultures were inoculated with $H$. guilliermondii pure cultures. Under these conditions, cells still died and much higher death rates were found for the 6 days than for the 3 day-old supernatants. This strongly indicates that one or more toxic compounds produced by $S$. cerevisiae triggers the early death of the $H$. guilliermondii cells in mixed cultures with $S$. cerevisiae. Finally, although it has not been yet possible to identify the nature of the toxic compounds involved in this phenomenon we must emphasise that the $S$. cerevisiae strain used in the present work is killer sensitive with respect to the classical killer toxins, K1, K2 and K28, whereas the H. guilliermondii and H. uvarum strains are killer neutral.
\end{abstract}

\section{Introduction}

Spontaneous wine fermentations are carried out by a succession of different yeast populations, the early stages being characterised by the growth of certain non-Saccharomyces yeasts belonging to the genera Candida, Kloeckera and Hanseniaspora and the latter stages being invariably dominated by alcoholtolerant strains of S. cerevisiae (Fleet and Heard, 1993; Pretorius, 2000). The growth of some of these non-Saccharomyces yeasts

\footnotetext{
* Corresponding author. Tel.: +351 210924600; fax: +351 210924721.

E-mail address: francisco.girio@ineti.pt (F. Girio).

${ }^{1}$ Contributed equally to the paper.
}

is nowadays considered to be beneficial to enhance the wine flavour due to higher production of important metabolites, such as glycerol, esters and higher alcohols (Romano et al., 1997; Egli et al., 1998; Granchi et al., 2002; Fleet, 2003). However, the growth of these non-Saccharomyces fermenting yeasts is generally limited to the first two or three days of fermentation, after which they begin to die off, giving way to strains of S. cerevisiae which conduct the fermentation exclusively until completion (Constantí et al., 1998; Pretorius, 2000).

The wine yeast population dynamics is generally ascribed to the higher capacity of Saccharomyces to withstand the changing environmental conditions of increasing ethanol and organic acids concentrations, decreasing $\mathrm{pH}$ and nutritional depletion 
(Pretorius, 2000). In addition, the initial microflora and the chemical composition (including fungicide and/or pesticide remains) of the grape musts, as well as extrinsic factors such as sulphur dioxide addition, fermentation temperature and the use of wine starters, exert a strong selective pressure on the survival of the yeast species along the wine fermentation process (Constantí et al., 1998; Henick-Kling et al., 1998; Ganga and Martínez, 2004). The predominant role of these classic selective pressures is currently being questioned and other, as yet undefined, microbe-microbe interactions are being put forward as potentially significant in influencing yeast successions (Ciani and Pepe, 2002; Fleet, 2003; Nissen and Arneborg, 2003).

There are several compounds produced by yeasts during alcoholic fermentations that may become inhibitory to other yeast species or strains. Aside from ethanol, certain metabolites such as short- to medium-chain fatty acids (e.g. acetic, hexanoic, octanoic and decanoic acids) can reach concentrations leading to cell death of certain yeast species, including some strains of S. cerevisiae (Ludovico et al., 2001; Fleet, 2003). Another inhibitory mechanism, which can occur in wine fermentations, is the so-called yeast killer activity (Shimizu, 1993; Vadasz et al., 2000; Pérez et al., 2001). This phenomenon consists in the production of specific extracellular glycoproteins by certain yeast strains (killer yeasts) that are able to kill other yeast strains (sensitive yeasts) (Woods and Bevan, 1968; Marquina et al., 2002; Schmitt and Breinig, 2002). Strains exhibiting killer-positive activity have been identified within different yeast genera associated with wine-making, including Saccharomyces, Hanseniaspora, Pichia, Candida, Kluyveromyces, Zygosaccharomyces, Metschnikowia and Cryptococcus (Chen et al., 2000; Ciani and Fatichenti, 2001).

In fermenting wine musts, oxygen and assimilable nitrogen can be rapidly depleted due to both semi-anaerobic growth conditions and poor initial nitrogen content of the grape juice. Hansen et al. (2001) reported that $T$. delbrueckii and $K$. thermotolerans are less tolerant to conditions of low available oxygen than $S$. cerevisiae. This observation is consistent with their early death during mixed fermentations with $S$. cerevisiae. On other hand, in wine fermentations where the initial microflora is mainly composed by non-Saccharomyces species, amino acid and vitamin consumption during the first days of fermentation can disable the subsequent growth of $S$. cerevisiae strains (Fleet, 2003).

In spite of the above-cited reports, the early death of nonSaccharomyces yeasts during mixed fermentations with $S$. cerevisiae strains has been scarcely described in the literature and usually is straightforward attributed to the lower ethanol tolerance of non-Saccharomyces by comparison to S. cerevisiae. Actually, only few thorough studies have been done aiming to elucidate the causes and the mechanisms underlying this phenomenon (Hansen et al., 2001; Nissen and Arneborg, 2003; Nissen et al., 2003). In the above-mentioned studies, the authors concluded that the early death of two wine-related yeasts $(K$. thermotolerans and T. delbrueckii) during mixed fermentations with $S$. cerevisiae was not due to the presence of ethanol or any other toxic compound but instead to a cell-cell contact-mediated mechanism. Pina et al. (2004) also reported that several $H$. guilliermondii and C. stellata strains could stand much higher ethanol concentrations than previously thought. Additionally, previous work carried out with three non-Saccharomyces wine strains (H. guilliermondii, $H$. uvarum and $C$. stellata) revealed that these yeast strains are poorly fermentative due to deficient sugar uptake that is, at least in some extent, related with a nutritional limitation and not to ethanol intolerance (Albergaria et al., 2003a,b).

Aiming to clarify these findings, in the present work the early death of two non-Saccharomyces wine-related yeasts (H. guilliermondii and H. uvarum) under mixed cultures with $S$. cerevisiae was investigated.

\section{Materials and methods}

Yeast strains, growth media and inoculation

\section{Microorganisms}

Hanseniaspora guilliermondii NCYC 2380 (previously isolated from Douro wine region, Portugal), H. uvarum PYCC 4193T (Portuguese Yeast Culture Collection, UNL, Lisbon) and Saccharomyces cerevisiae CCMI 885 (Culture Collection of Industrial Microorganisms, INETI, Lisbon) were examined in the present study. Strains were routinely maintained at $4{ }^{\circ} \mathrm{C}$ on YEPD-agar slants (containing $20 \mathrm{~g}$ $1^{-1}$ glucose, $10 \mathrm{~g} \mathrm{l}^{-1}$ yeast extract, $20 \mathrm{~g} \mathrm{l}^{-1}$ peptone and $20 \mathrm{~g}$ $1^{-1}$ agar).

\section{Cultivation media}

Inoculum cultures were done in YEPD medium (containing $10 \mathrm{~g} \mathrm{l}^{-1}$ yeast extract, $20 \mathrm{~g} \mathrm{l}^{-1}$ peptone and $20 \mathrm{~g} \mathrm{l}^{-1}$ glucose). The single- and mixed-cultures performed with an initial sugar concentration of $200 \mathrm{~g} \mathrm{l}^{-1}$ were cultivated in a modified synthetic grape juice media (SGJ), previously described by Ciani and Ferraro (1996). Each litre of SGJ was composed of three different solutions: solution A $(500 \mathrm{ml})$, solution B $(250 \mathrm{ml})$, and solution C $(250 \mathrm{ml})$. The final composition of SGJ was as follows (per litre): (from solution A) D-glucose, $110 \mathrm{~g}$; D-fructose, $110 \mathrm{~g}$; (from solution B) L-(1)-tartaric acid, $6.0 \mathrm{~g}$; L-(2)-malic acid, $3.0 \mathrm{~g}$; citric acid, $0.5 \mathrm{~g}$; (from solution C) YNB (yeast nitrogen base without amino acids and ammonium sulfate) (Difco), $1.7 \mathrm{~g}$; CAA (vitamin-free Casamino Acids) (Difco), $2.0 \mathrm{~g} ; \mathrm{CaCl}_{2}, 0.2 \mathrm{~g}$; arginine-HCl, $0.8 \mathrm{~g}$; L-(2)-proline, $1.0 \mathrm{~g}$; L-(2)-tryptophan, $0.1 \mathrm{~g}$. Solutions $\mathrm{B}$ and $\mathrm{C}$ were buffered at $\mathrm{pH} 3.5$ with $\mathrm{NH}_{4} \mathrm{OH}$ and $\mathrm{H}_{3} \mathrm{PO} 4$, respectively. The three solutions were sterilized separately at $121{ }^{\circ} \mathrm{C}$ for $20 \mathrm{~min}$ and then combined aseptically. At last, the medium was supplemented with $3 \mathrm{~g} \mathrm{l}^{-1}$ of both sterile yeast extract and peptone.

The mixed cultures performed with $H$. guilliermondii and $S$. cerevisiae at an initial sugar (fructose + glucose) concentration of $100 \mathrm{~g} \mathrm{l}^{-1}$ were cultivated in the same medium described above but using in solution $A$ only half of both sugar concentration.

\section{Inoculation cultures}

In preparing the inoculum cultures of $H$. guilliermondii, $H$. uvarum and S. cerevisiae, cells from one YEPD-agar slant (pre- 
grown for $48 \mathrm{~h}$ at $30{ }^{\circ} \mathrm{C}$ ) were transferred to $50 \mathrm{ml}$ YEPD medium in $100 \mathrm{ml}$ shake flasks and incubated at $30{ }^{\circ} \mathrm{C}$ with $150 \mathrm{rpm}$ of agitation for $16 \mathrm{~h}$.

\section{Single and mixed fermentations performed with $200 \mathrm{gl}^{-1}$ of initial sugar}

All mixed and single cultures were performed under semianaerobic growth conditions, in 2 l-erlenmeyers containing 1.5 1 of synthetic grape juice (SGJ) at $18{ }^{\circ} \mathrm{C}$ without agitation. All single fermentations, $H$. guillermondii, $H$. uvarum and $S$. cerevisiae, were inoculated at an initial cell concentration of $10^{6} \mathrm{CFU} \mathrm{ml}{ }^{-1}$. The mixed fermentation of $H$. uvarum with $S$. cerevisiae was inoculated with $7 \times 10^{5}$ and $3 \times 10^{6} \mathrm{CFU} \mathrm{ml}^{-1}$, respectively. The mixed fermentations of $H$. guillermondii $(\mathrm{Hg})$ with $S$. cerevisiae $(\mathrm{Sc})$ were inoculated with initial cell concentration of $(\mathrm{Sc} / \mathrm{Hg}): 1.4 \times 10^{6} / 5.4 \times 10^{5} \mathrm{CFU} \mathrm{ml} \mathrm{m}^{-1}$; $2.2 \times 10^{6} / 4.1 \times 10^{6} \mathrm{CFU} \mathrm{ml}^{-1} ; 1.0 \times 10^{4} / 3.8 \times 10^{5} \mathrm{CFU} \mathrm{ml}^{-1}$; $6.0 \times 10^{1} / 5.7 \times 10^{3} \mathrm{CFU} \mathrm{m}{ }^{-1}$. Samples were taken daily for viable cell counts and quantification of glucose, fructose and ethanol concentrations.

\section{Mixed fermentations performed with $100 \mathrm{gl}^{1}$ \\ of initial sugar}

Two mixed cultures of $H$. guillermondii $(\mathrm{Hg})$ with $S$. cerevisiae $(\mathrm{Sc})$ were carried out in the same growth conditions as described for the $200 \mathrm{~g} \mathrm{l}^{-1}$ single and mixed fermentations, with an initial sugar concentration of $100 \mathrm{~g} \mathrm{l}^{-1}$. One of the cultures was performed at an initial $(\mathrm{Sc} / \mathrm{Hg})$ cell ratio of $1.5 \times 10^{6} / 2.8 \times 10^{6} \mathrm{CFU} \mathrm{m}{ }^{-1}$ and the other at $1.0 \times 10^{5} /$ $2.9 \times 10^{6} \mathrm{CFU} \mathrm{ml}^{-1}$, respectively. Samples were taken daily for viable cell counts and quantification of glucose, fructose and ethanol concentrations.

\section{H. guilliermondii cultivation on cell-free supernatants}

Cell-free supernatants were obtained from sterile filtration (0.22 $\mu \mathrm{m}$ Millipore membranes) of one $\mathrm{Hg}$ single-culture, previously fermented during 8 days, and two $\mathrm{Sc} / \mathrm{Hg}$ mixed cultures fermented for 3 and 6 days, respectively. Supernatants were supplemented with nitrogen source $\left(\left[\mathrm{NH}_{4}\right]_{2} \mathrm{HPO}_{4}\right)$, vitamins, salts and yeast extract to avoid nutritional limitations. All cell-free supernatants were inoculated with $10^{6} \mathrm{CFU} \mathrm{ml}{ }^{-1}$ of pure $\mathrm{Hg}$ cultures (pre-grown for $16 \mathrm{~h}$ at $30^{\circ} \mathrm{C}$ and $150 \mathrm{rpm}$ ) and cultivated in the same growth conditions used for single and mixed fermentations.

\section{Analysis of growth}

The yeasts growth during the fermentations was obtained by viable cell quantification using the classical plate count method. Samples were taken aseptically throughout the fermentations and diluted appropriately in distilled water. In the mixed fermentations, the enumeration of $H$. guilliermondii as well as $H$. uvarum cells were performed using YEPD-agar medium supplemented with $2 \mu \mathrm{g} \mathrm{ml}^{-1}$ of cycloheximide (YEPD $+\mathrm{CYH}$ )
(Pérez et al., 2000). The number of S. cerevisiae viable cells in the mixed cultures was given as the difference between the total number of colonies on YEPD-agar plates and the total number of colonies on YEPD $+\mathrm{CYH}$ plates. YEPD-agar and YEPD $+\mathrm{CYH}$ plates were incubated at $30{ }^{\circ} \mathrm{C}$ for $2-4$ days and enumeration was determined after no increase in colony forming units (CFU) was observed. Preliminary enumerations of single cultures of $H$. guilliermondii and H. uvarum were done on both YEPD-agar and YEPD $+\mathrm{CYH}$ medium and similar $\mathrm{CFU}$ numbers were obtained (data not shown). In addition, $H$. guilliermondii and $S$. cerevisiae viable cell enumeration during mixed cultures using direct plating on YEPD-agar ( $\mathrm{CFU}$ of $\mathrm{Hg}+\mathrm{Sc}$ ) followed by replica-plating on YEPD $+\mathrm{CYH}$ plates $(\mathrm{CFU}$ of $\mathrm{Hg}$ ) gave similar results to enumerations obtained from separated inoculation on YEPD-agar (CFU of $\mathrm{Hg}+\mathrm{Sc})$ and on $\mathrm{YEPD}+\mathrm{CYH}(\mathrm{CFU}$ of $\mathrm{Hg})$ plates (data not shown).

\section{Analytical assays}

Cell-free samples (filtration through $0.45 \mu \mathrm{m}$ Millipore membranes) were used to analyse different substrates and metabolites of all fermentations. Ethanol, glucose and fructose were determined by HPLC (Merck Hitachi, Darmstadt, Germany) using a Sugar-Pak ${ }^{\mathrm{TM}}$ column (Waters, Milford, USA) connected to a RI detector (L-7490, Merck Hitachi, Darmstadt, Germany). The column was eluted at $70^{\circ} \mathrm{C}$ with a degassed aqueous mobile phase containing $50 \mathrm{mg} \mathrm{l}^{-1} \mathrm{CaEDTA}$, at a flow rate of $0.5 \mathrm{ml}$ $\min ^{-1}$. All samples were analysed in duplicate.

\section{Killer activity strain screenings}

For killer activity screening several $S$. cerevisiae reference strains for killer and sensitive traits were used: K1 killer strain (JCR2, obtained from Dr. R.B. Wickner, Section of Genetics of Simple Eukaryotes, National Institute of Diabetes, Digestive and Kidney Diseases, NIH Bethesda, MD 20892, USA); K2 killer (EX85, S. cerevisiae industrial wine strain isolated and selected by Regodón et al., 1997), K28 killer (GY-2-3a obtained from Manfred Schmitt, Angewandte Molekularbiologie, Univesität des Saarlandes, Im Sadtwadl, Gebäude 2, D-66123 Saarbrücken, Germany); killer sensitive (EX33, S. cerevisiae industrial wine strain, isolated and selected by Regodón et al., 1997).

The tests were performed as described by Boone et al. (1990). Plates of MB $(0.5 \%$ yeast extract, $1 \%$ peptone, $2 \%$ glucose, $2 \%$ agar, $0.003 \%$ methylene blue, $0.1 \mathrm{M}$ sodium citrate) with different $\mathrm{pH}$ values ( $\mathrm{pH} 3.5,3.7,4.0,4.3,4.7)$ were seeded with killer-sensitive strains (pre-grown for $48 \mathrm{~h}$ on YEPD-agar slants). Strains to be tested for killer activity were loaded onto the seeded agar. Colonies exhibiting clear halos on the sensitive lawns after $3-7$ days of incubation at $20^{\circ} \mathrm{C}$ were considered to be killer positive. To test killer-sensitive traits, MB plates were seeded with the strains to be tested and overlaid with K2, K1 and K28 killer strains. Strains exhibiting clear halos on the plates were considered to be killer sensitive towards the respective reference killer strains $(\mathrm{K} 1, \mathrm{~K} 2$ and K28). 


\section{Results and discussion}

.Early death of $\mathrm{H}$. guilliermondii and $\mathrm{H}$. uvarum in mixed fermentations with $\mathrm{S}$. cerevisiae

Single cultures of $H$. guilliermondii, $H$. uvarum and $S$. cerevisiae and mixed cultures of $S$. cerevisiae/H. guilliermondii and $S$. cerevisiae/H. uvarum were performed in synthetic grape juice (SGJ) under semi-anaerobic growth conditions. Viable cells, sugar consumption and ethanol production profiles of single and mixed cultures are compared in Figs. 1 and 2. The early death of $H$. guilliermondii and $H$. uvarum was observed at the beginning of both fermentations. In the mixed culture of $S$. cerevisiae/H. guilliermondii, both yeasts grew together during the first day of fermentation with similar maximum specific growth rates, attaining $10^{7} \mathrm{CFU} \mathrm{ml}{ }^{-1}$ (Fig. 1-C). Then, $H$. guilliermondii cells began to die off and death was complete (less than $1 \mathrm{CFU} \mathrm{ml}{ }^{-1}$ ) within 7-8 days of fermentation. In the mixed culture of $S$. cerevisiae/H. uvarum, $H$. uvarum was unable to grow and the onset of death was observed immediately after the first day of fermentation, being complete within 2-3 days (Fig. 2-C). This faster death effect was possibly due to the higher S. cerevisiae/H.uvarum inoculum ratio in comparison with the one used for $S$. cerevisiae/guilliermondii mixed culture. Conversely, in the single cultures of these nonSaccharomyces yeasts (Figs. 1-A and 2-A) the number of viable cells remained at concentrations close to $10^{7}-10^{8} \mathrm{CFU} \mathrm{ml}{ }^{-1}$ during a much longer fermentation time (20 days in the $H$. guilliermondii culture and 15 days in the $H$. uvarum culture).

It is generally accepted that non-Saccharomyces yeasts begin to die off during the early stages of spontaneous wine fermentations due to their inability to tolerate the increasing ethanol concentrations present in the must medium (Egli et al., 1998; Cocolin et al., 2000; Fleet, 2003). However, recent
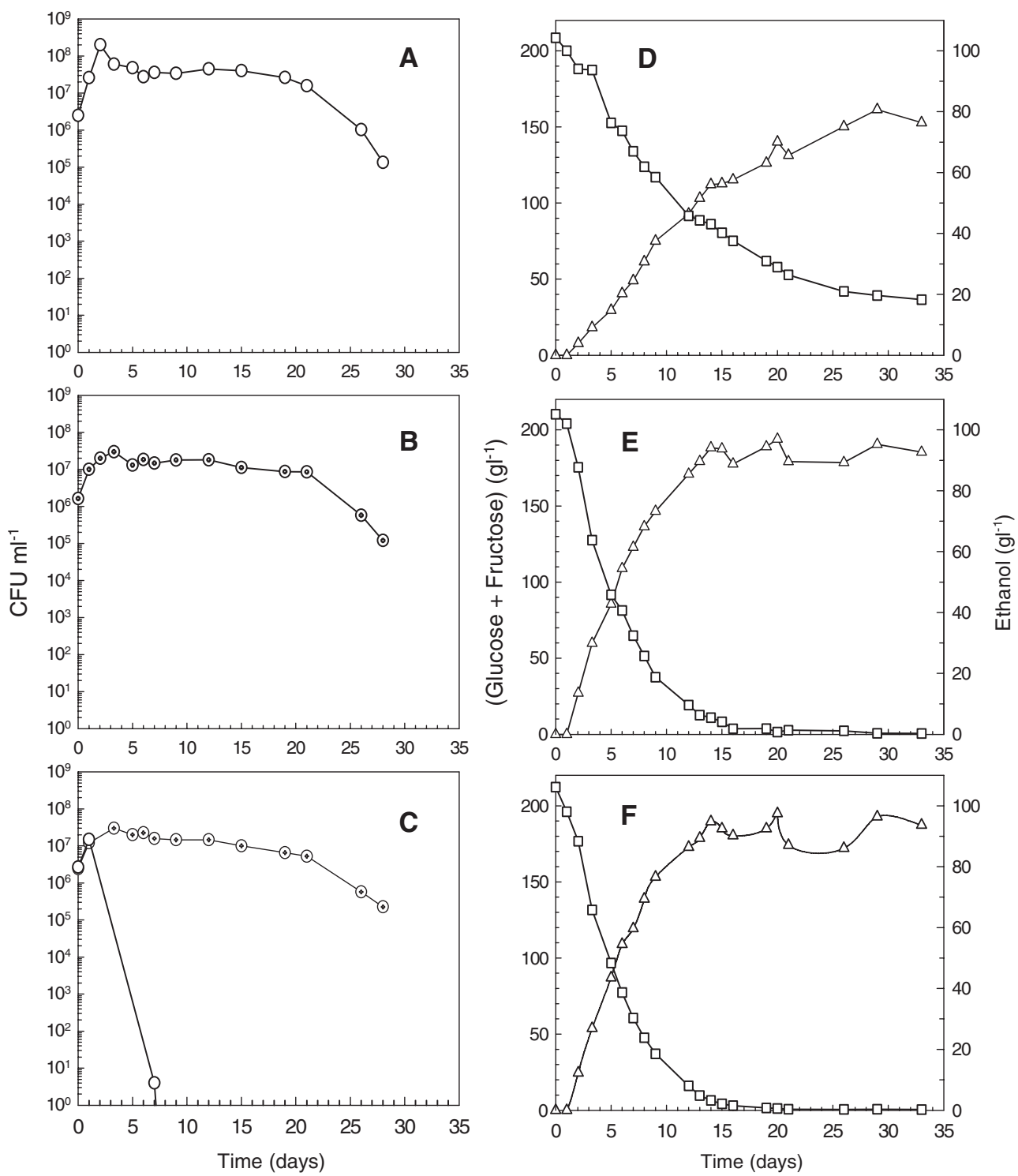

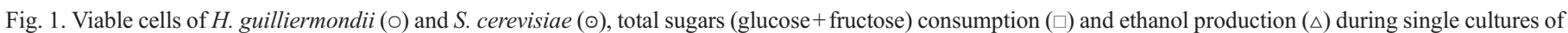
H. guilliermondii (A,D) and S. cerevisiae (B,E) and mixed culture of H. guilliermondii with S. cerevisiae (C,F). 

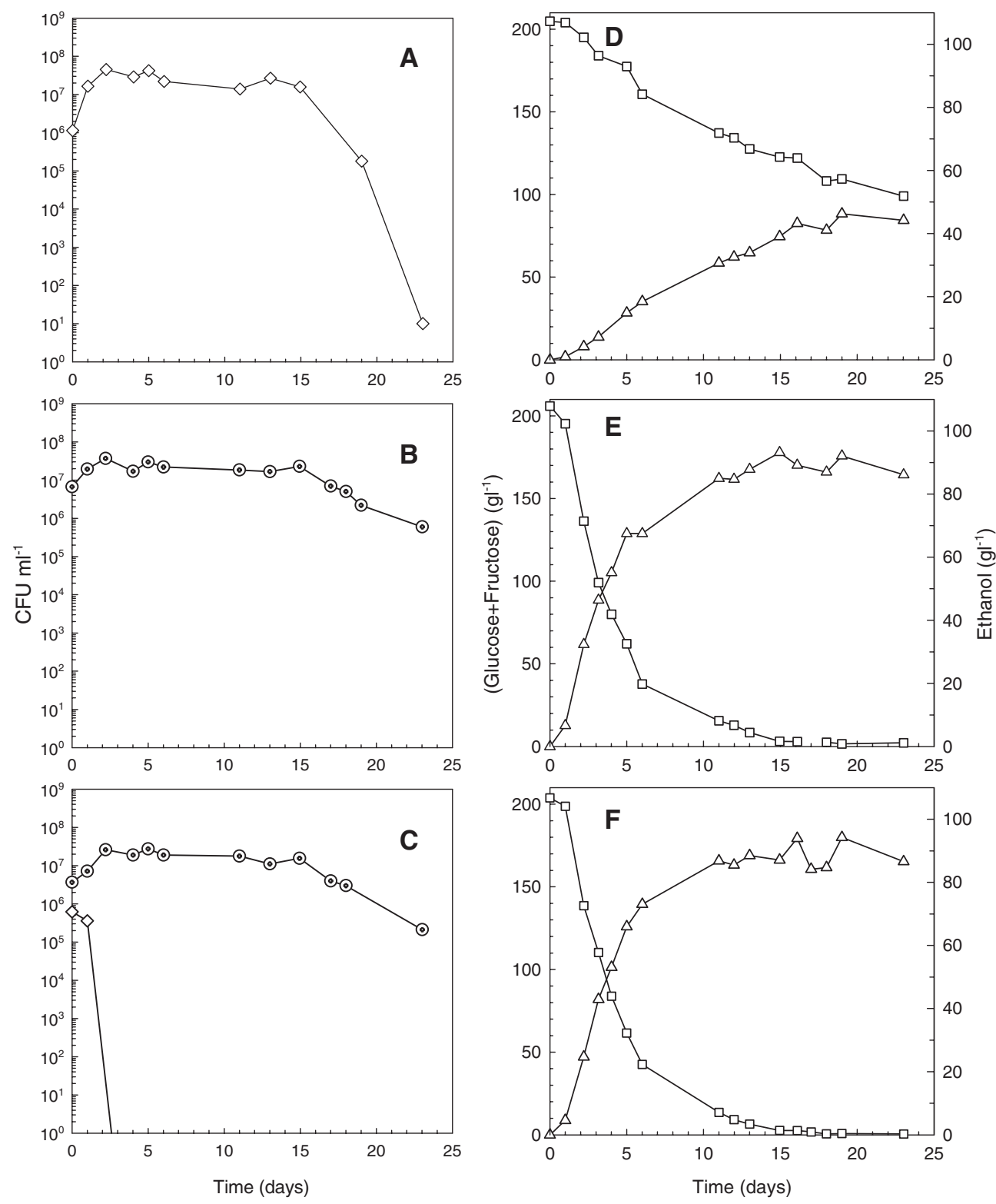

Fig. 2. Viable cells of $H$. uvarum $(\diamond)$ and $S$. cerevisiae $(\odot)$, glucose and fructose consumption $(\square)$ and ethanol production $(\triangle)$ during single cultures of $H$. uvarum $(\mathrm{A}, \mathrm{D})$ and $S$. cerevisiae $(\mathrm{B}, \mathrm{E})$ and mixed culture of H. uvarum with S. cerevisiae $(\mathrm{C}, \mathrm{F})$.

studies have demonstrated that $H$. guilliermondii is able to stand much higher ethanol concentrations than previously thought (Pina et al., 2004). Explanations for the early death of nonSaccharomyces yeasts in mixed cultures with Saccharomyces spp., could rely upon several of factors: competition for sugar uptake, oxygen availability, nutrient limitation, presence of toxic compounds, cell-cell contact, quorum sensing (Hansen et al., 2001; Fleet, 2003; Nissen and Arneborg, 2003; Nissen et al., 2003).

The sugar and ethanol concentrations present in the $S$. cerevisiae/H. guilliermondii mixed fermentation at the onset of the non-Saccharomyces death (Fig. 1-F) were 177 and $12 \mathrm{~g} \mathrm{l}^{-1}$, respectively, and in the $S$. cerevisiae/H. uvarum mixed fermentation (Fig. 2-F) were 195 and $6.6 \mathrm{~g} \mathrm{l}^{-1}$, respectively. In the single cultures, however, $H$. guilliermondii and $H$. uvarum viable cell concentrations remained at high values (ranging $10^{7}-10^{8} \mathrm{CFU} \mathrm{ml}^{-1}$ ) during $15-20$ days of fermentation, even when ethanol had reached relatively high concentrations (60-70 $\left.\mathrm{g} \mathrm{l}^{-1}\right)$ (Figs. 1-D and 2-D). These results seem to indicate that the early death of non-Saccharomyces in mixed growth with $S$. cerevisiae was not caused by nutrient limitation or high ethanol concentrations in the culture medium. Rojas et al. (2003) found that, for mixed cultures of $H$. guilliermondii and/or $P$. anomala with $S$. cerevisiae, the onset of the non-Saccharomyces death always began after the initial 1-2 days of fermentation, which agrees well with our results. Moreover, Nissen and Arneborg (2003) reported similar results for two non-Saccharomyces wine yeasts (Kluyveromyces thermotolerans and Torulospora debruecki) in mixed cultures with $S$. cerevisiae. These authors suggested that viable $S$. cerevisiae cells at high concentrations provoke the early death of non-Saccharomyces 
yeasts in mixed cultures by a cell-to-cell contact-mediated mechanism.

In the current study, the early death of $H$. guilliermondii and $H$. uvarum yeasts in mixed growth with $S$. cerevisiae was also confirmed under different cultivation conditions, namely aerobic growth and different culture media, and tested against several S. cerevisiae strains (data not shown). These findings led us to conclude that this early death is not dependent of the growth conditions or of a specific $S$. cerevisiae strains but it is rather related to the physical presence of $S$. cerevisiae cells and/
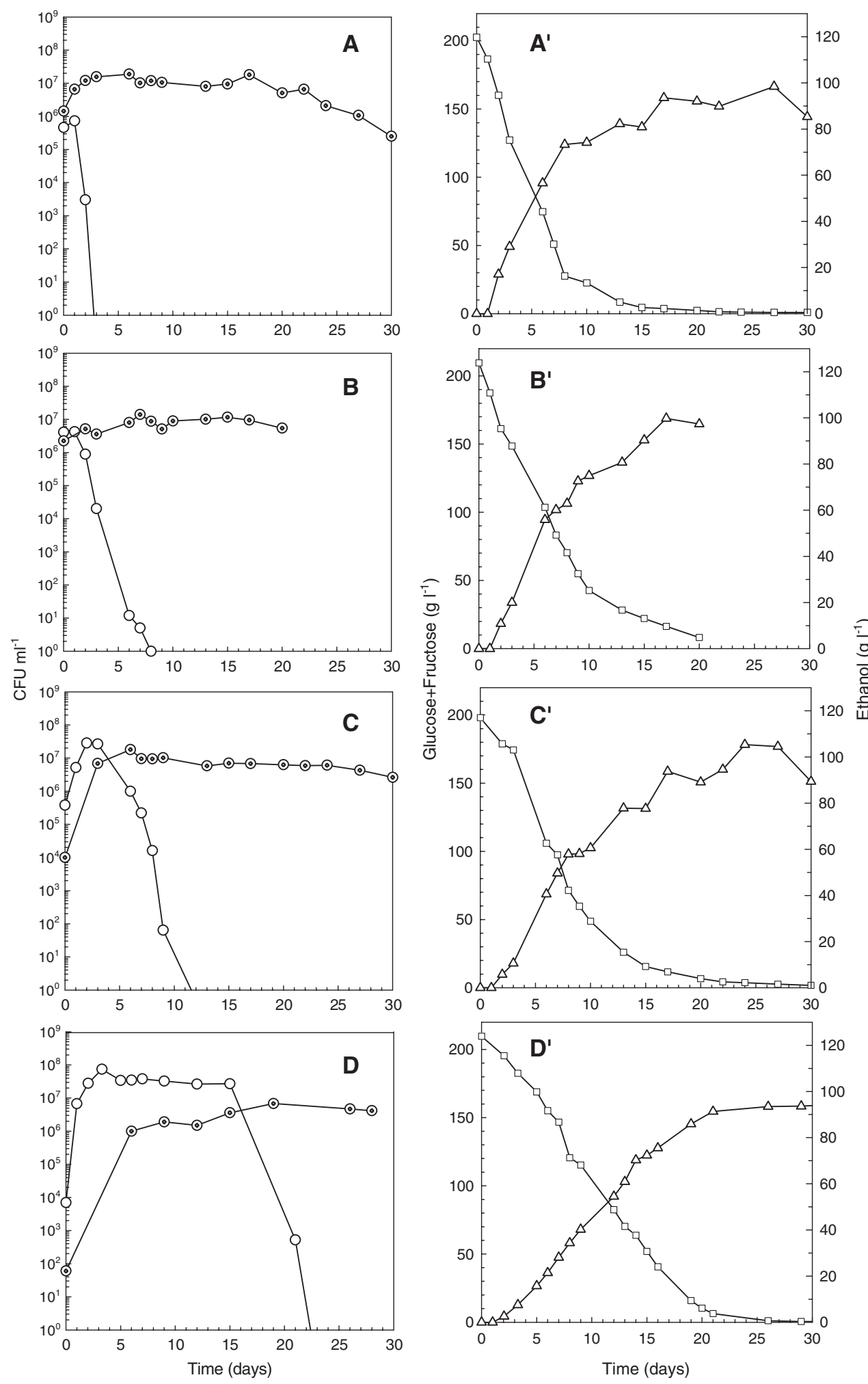

Fig. 3. Viable cells of H. guilliermondii $(\mathrm{Hg})(\circ)$ and $S$. cerevisiae $(\mathrm{Sc})(\odot)$, glucose and fructose consumption $(\square)$ and ethanol production $(\triangle)$, during the mixed cultures performed with different $(\mathrm{Sc} / \mathrm{Hg})$ inoculum ratios: $\mathrm{A}, \mathrm{A}^{\prime}-(3: 1) ; \mathrm{B}, \mathrm{B}^{\prime}-(1: 2) ; \mathrm{C}, \mathrm{C}^{\prime}-(1: 10) ; \mathrm{D}, \mathrm{D}^{\prime}-(1: 100)$. 
Table 1

Relation between the initial $\mathrm{Sc} / \mathrm{Hg}$ inoculum ratio and the onset of the $\mathrm{Hg}$ cell death in each $\mathrm{Sc} / \mathrm{Hg}$ mixed culture plotted in Fig. 3

\begin{tabular}{|c|c|c|c|c|}
\hline \multirow{2}{*}{$\begin{array}{l}\text { Plots } \\
\text { in } \\
\text { Fig. } 3\end{array}$} & \multicolumn{2}{|c|}{$\begin{array}{l}\text { Initial cell density } \\
\left(\mathrm{CFU} \mathrm{ml}^{-1}\right)\end{array}$} & \multirow{2}{*}{$\begin{array}{l}\text { Initial day } \\
\text { of } \mathrm{Hg} \text { cell } \\
\text { death }\end{array}$} & \multirow{2}{*}{$\begin{array}{l}\text { S. cerevisiae cell } \\
\text { density at initial day } \\
\text { of death }\left(\mathrm{CFU} \mathrm{ml} \mathrm{m}^{-1}\right)\end{array}$} \\
\hline & S. cerevisiae & H. guilliermondii & & \\
\hline A & $1.4 \times 10^{6}$ & $5.4 \times 10^{5}$ & 1 & $6.6 \times 10^{6}$ \\
\hline B & $2.2 \times 10^{6}$ & $4.1 \times 10^{6}$ & 2 & $5.1 \times 10^{6}$ \\
\hline $\mathrm{C}$ & $1.0 \times 10^{4}$ & $3.8 \times 10^{5}$ & 3 & $6.9 \times 10^{6}$ \\
\hline $\mathrm{D}$ & $6.0 \times 10^{1}$ & $5.7 \times 10^{3}$ & 15 & $3.6 \times 10^{6}$ \\
\hline
\end{tabular}

or toxic agents produced by them against other non-Saccharomyces yeasts.

\section{.Effect of S. cerevisiae viable cells concentration on the cell} death process

In order to evaluate the influence of $S$. cerevisiae cell density on the non-Saccharomyces death process, several mixed cultures were performed using different $S$. cerevisiae/H. guilliermondii $(\mathrm{Sc} / \mathrm{Hg})$ inoculum ratios $(3: 1) ;(1: 2) ;(1: 10) ;(1: 100)$.

Viable cell concentrations of $H$. guilliermondii and $S$. cerevisiae of these mixed cultures and the corresponding sugars and ethanol profiles, throughout the cultivation period, are represented on Fig. 3. Plots A-D show the relationship between death kinetics and initial $\mathrm{Sc} / \mathrm{Hg}$ cell concentration ratio. In all mixed cultures, Saccharomyces became dominant at the end of the fermentation but $H$. guilliermondii death began, and was completed, at varying stages of the fermentation depending on the initial $\mathrm{Sc} / \mathrm{Hg}$ cell concentration ratio (Fig. 3). Results show that death rates of $H$. guilliermondii in the mixed cultures increased for higher $\mathrm{Sc} / \mathrm{Hg}$ inoculum ratios and death process began sooner: at the first day of fermentation for the initial inoculum ratio of $(3: 1)$ and after 15 days for the initial inoculum ratio of $(1: 100)$.

Comparing $S$. cerevisiae with $H$. guilliermondii cell profiles (Fig. 3, plots A-D) it can be observed that the onset of the non-Saccharomyces death depends, not only from the initial relative proportions of $S$. cerevisiae/H. guilliermondii but also from the $S$. cerevisiae cell density value present in the mixed cultures. In fact, $H$. guilliermondii death in the mixed cultures occurred only when $S$. cerevisiae cell density reached values close to $10^{7} \mathrm{CFU} \mathrm{ml}^{-1}$. The initial number of viable cells, the initial day of $H$. guilliermondii death process and the corresponding $S$. cerevisiae cell density in the mixed cultures are summarised in Table 1.

Once again, it is clear that the sugars and ethanol concentrations were not the primary cause of $H$. guilliermondii death (Fig. 3, plots $\mathrm{A}^{\prime}-\mathrm{D}^{\prime}$ ). In fact, at the onset of $\mathrm{Hg}$ death the sugars and ethanol concentrations were $187 \mathrm{~g} \mathrm{l}^{-1}$ and $0 \mathrm{~g} \mathrm{l}^{-1}$, respectively, in the $(3: 1) \mathrm{Sc} / \mathrm{Hg}$ mixed culture (Fig. 3- $\left.\mathrm{A}^{\prime}\right)$ and $52 \mathrm{~g} \mathrm{l}^{-1}$ and $72 \mathrm{~g} \mathrm{l}^{-1}$, respectively, in the $(1: 100) \mathrm{Sc} / \mathrm{Hg}$ mixed culture (Fig. 3-D'). These results prove that the early death of $H$. guilliermondii is highly dependent of the $S$. cerevisiae concentration and two explanations suggest themselves: production of toxic compounds, other than ethanol, by S. cerevisiae, or cell-
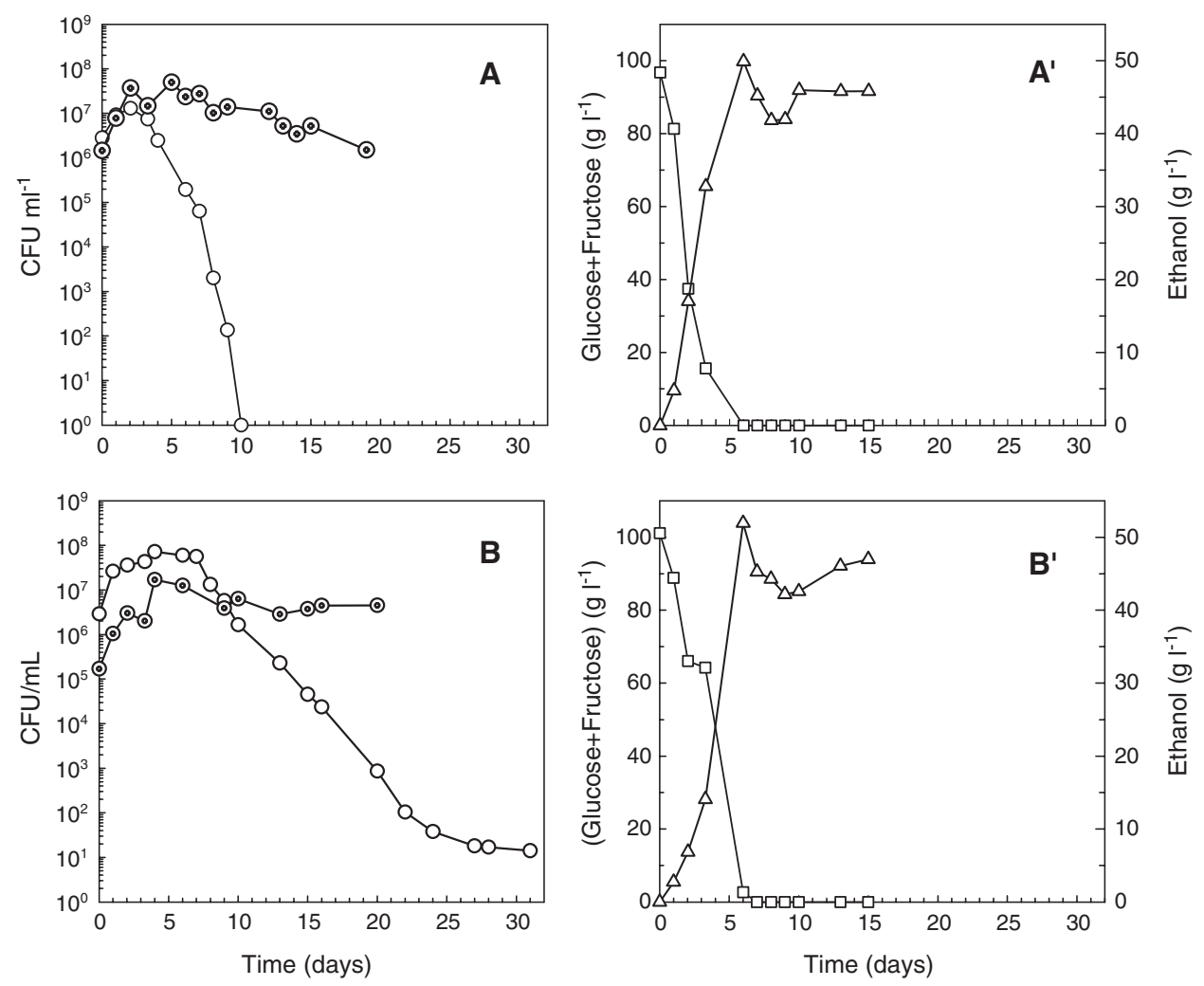

Fig. 4. Viable cells of H. guilliermondii $(\odot)$ and S. cerevisiae $(\odot)$, glucose and fructose consumption $(\square)$ and ethanol production $(\triangle)$ during the mixed cultures performed with $100 \mathrm{~g} \mathrm{l}^{-1}$ of initial total sugars at different $(\mathrm{Sc} / \mathrm{Hg})$ inoculums ratios: $\mathrm{A}, \mathrm{A}^{\prime}-(1: 2) ; \mathrm{B}, \mathrm{B}^{\prime}-(1: 10)$. 
to-cell contact, as previously reported by Nissen et al. (2003) and Nissen and Arneborg (2003).

The amount of sugar metabolised by $S$. cerevisiae had a pronounced effect on the death rate of $H$. guilliermondii in mixed cultures. In fact, for the mixed culture performed with $100 \mathrm{~g}^{-1}$ of initial sugars ( $\mathrm{Sc} / \mathrm{Hg}$ inoculum ratio $\approx 1: 10$ ), the viable cells concentrations of $H$. guilliermondii remained at values close to $10^{8} \mathrm{CFU} \mathrm{ml}{ }^{-1}$ until the 7th day of fermentation and death was not completed, at least, during the first 34 days of fermentation (Fig. 4-B). Whereas in the mixed culture performed with $200 \mathrm{~g} \mathrm{l}^{-1}$ of initial sugars (similar inoculum ratio) $H$. guilliermondii death began on the 4th day of fermentation and was completed within $12-13$ days (Fig. 3-C). A similar delay on the onset of cellular death was observed when a mixed culture was grown at $(1: 2)$ inoculum ratio $(\mathrm{Sc} / \mathrm{Hg})$ using $100 \mathrm{~g}^{-1}$ instead of $200 \mathrm{~g} \mathrm{l}^{-1}$ of initial total sugars (Fig. 4-A compares with Fig. 3-B), although $S$. cerevisiae caused the total death of $H$. guilliermondii cells in both situations. Cell densities achieved by $S$. cerevisiae in the mixed fermentations performed with $100 \mathrm{~g} \mathrm{l}^{-1}$ of initial sugars were similar to those found in the mixed fermentations performed with $200 \mathrm{~g} \mathrm{l}^{-1}$ (above $10^{7} \mathrm{CFU} \mathrm{m}{ }^{-1}$ ), but $H$. guilliermondii death was retarded in the former case when compared to the latter. Thus, apparently, death of $H$. guilliermondii depends not only on the S. cerevisiae cell density but also on the amount of sugar metabolised. These findings suggest that one or more toxic compounds produced by $S$. cerevisiae is/are the cause of the early death of $H$. guilliermondii during mixed growths with $S$. cerevisiae.

It should be mentioned that the overall behaviour of the different yeast species in the mixed fermentations performed agree well with the yeast population dynamics found in spontaneous and inoculated wine fermentations. Several studies (Constantí et al., 1998; Cocolin et al., 2000; Raspor et al., 2002) report the dominance of non-Saccharomyces yeasts during the firsts days (3-7 days) of spontaneous vinifications, where the initial yeast population ranges $10^{4}-10^{5} \mathrm{CFU} \mathrm{ml} \mathrm{m}^{-1}$ for nonSaccharomyces yeasts and $10^{2}-10^{3} \mathrm{CFU} \mathrm{m}{ }^{-1}$ for Saccharomyces yeasts. This performance is similar to the yeast behaviour exhibited in the mixed fermentations represented in Fig. 3-C and D. Conversely, in vinifications where $S$. cerevisiae starters

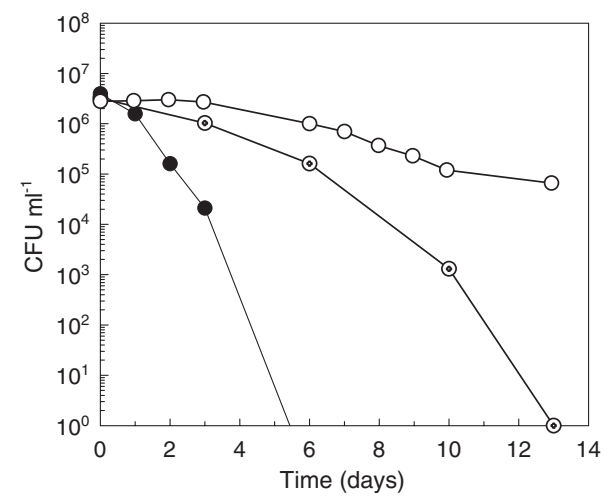

Fig. 5. Viable cells profiles of $H$. guillermondii inoculated in free-cell supernatants obtained from previous 8 day-old $\mathrm{Hg}$ single-culture (०), 3 dayold $\mathrm{Sc} / \mathrm{Hg}$ mixed culture $(\odot)$ and 6 day-old $\mathrm{Sc} / \mathrm{Hg}$ mixed culture $(\bullet)$.
Table 2

Killer activity tests performed for $S$. cerevisiae CCMI 885, H. guillermondii NCYC 2380 and $H$. uvarum PYCC 4193T with the reference strains, K1 killer JCR2, K2 killer EX85, K28 killer GY-2-3a and killer-sensitive EX33

\begin{tabular}{llllll}
\hline Strains & \multicolumn{4}{l}{ Killer activity at different $\mathrm{pH}$} & \\
\cline { 2 - 6 } & 3.5 & 3.7 & 4.0 & 4.3 & 4.7 \\
\hline H. guillermondii & $\mathrm{N} 1$ & $\mathrm{~N} 1$ & $\mathrm{~N} 1$ & $\mathrm{~N} 1$ & $\mathrm{~N} 1$ \\
& $\mathrm{~N} 2$ & $\mathrm{~N} 2$ & $\mathrm{~N} 2$ & $\mathrm{~N} 2$ & $\mathrm{~N} 2$ \\
& $\mathrm{~N} 28$ & $\mathrm{~N} 28$ & $\mathrm{~N} 28$ & $\mathrm{~N} 28$ & $\mathrm{~N} 28$ \\
& $\mathrm{~N} 33$ & $\mathrm{~N} 33$ & $\mathrm{~N} 33$ & $\mathrm{~N} 33$ & $\mathrm{~N} 33$ \\
H. uvarum & $\mathrm{N} 1$ & $\mathrm{~N} 1$ & $\mathrm{~N} 1$ & $\mathrm{~N} 1$ & $\mathrm{~N} 1$ \\
& $\mathrm{~N} 2$ & $\mathrm{~N} 2$ & $\mathrm{~N} 2$ & $\mathrm{~N} 2$ & $\mathrm{~N} 2$ \\
& $\mathrm{~N} 28$ & $\mathrm{~N} 28$ & $\mathrm{~N} 28$ & $\mathrm{~N} 28$ & $\mathrm{~N} 28$ \\
& $\mathrm{~N} 33$ & $\mathrm{~N} 33$ & $\mathrm{~N} 33$ & $\mathrm{~N} 33$ & $\mathrm{~N} 33$ \\
S. cerevisiae & $\mathrm{S} 1$ & $\mathrm{~S} 1$ & $\mathrm{~S} 1$ & $\mathrm{~S} 1$ & $\mathrm{~S} 1$ \\
& $\mathrm{~S} 2$ & $\mathrm{~S} 2$ & $\mathrm{~S} 2$ & $\mathrm{~S} 2$ & $\mathrm{~S} 2$ \\
& $\mathrm{~S} 28$ & $\mathrm{~S} 28$ & $\mathrm{~S} 28$ & $\mathrm{~S} 28$ & $\mathrm{~S} 28$ \\
& $\mathrm{~N} 33$ & $\mathrm{~N} 33$ & $\mathrm{~N} 33$ & $\mathrm{~N} 33$ & $\mathrm{~N} 33$ \\
\hline
\end{tabular}

N1: Killer neutral with respect to K1 killer toxin; N2: Killer neutral with respect to K2 killer toxin; N28: Killer neutral with respect to K28 killer toxin; N33: Killer neutral with respect to killer-sensitive strain EX33; S1: Killer sensitive with respect to $\mathrm{K} 1$ killer toxin; S2: Killer sensitive with respect to K2 killer toxin; S28: Killer sensitive with respect to K28 killer toxin.

are added to the musts at an initial cell concentration of $10^{6} \mathrm{CFU} \mathrm{ml}{ }^{-1}$, the $S$. cerevisiae dominance is established within the firsts 1-2 days, which compares well with the results obtained in the mixed cultures A and B (Fig. 3-A,B).

\section{Presence of toxic compounds}

In order to investigate the cause of the non-Saccharomyces early death, cell-free supernatants obtained from 3 and 6 daysold mixed cultures $(\mathrm{Hg}+\mathrm{Sc})$ and from an 8 days-old single culture of $\mathrm{Hg}$ were inoculated with $\mathrm{H}$. guilliermondii at an initial cell density of $10^{6} \mathrm{CFU} \mathrm{ml}^{-1}$. The viable cell profiles of these cultures (Fig. 5) showed that total death of $H$. guilliermondii was achieved within 5 and 13 days when cultivated in the 6 and 3 day-old mixed culture supernatants, respectively. Conversely, when cultivated in the $\mathrm{Hg}$ singleculture supernatant, cell viability remained relatively stable during 13 days, with a slight decrease being observed from an initial cell density of $2 \times 10^{6} \mathrm{CFU} \mathrm{ml}^{-1}$ to a final cell density of $8 \times 10^{4} \mathrm{CFU} \mathrm{ml}^{-1}$. The initial content of sugars and ethanol in the mixed cultures supernatants were 138 and $26 \mathrm{~g} \mathrm{l}^{-1}$, respectively, in the 3 day-old supernatant and 74 and $58 \mathrm{~g}^{-1}$, respectively, in the 6 day-old supernatant. It should be pointed out that the latter values compare with those initially present on
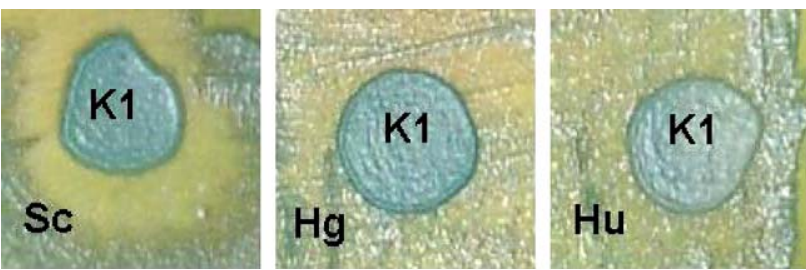

Fig. 6. Pictures of the killer activity plate tests performed for $S$. cerevisiae CCMI 885 (Sc), H. guillermondii NCYC $2380(\mathrm{Hg})$ and H. uvarum PYCC $4193 \mathrm{~T}(\mathrm{Hu})$ with the reference killer strain (K1). 
the $\mathrm{Hg}$ single-culture supernatant (initial concentration of sugars and ethanol of 67 and $52 \mathrm{~g} \mathrm{l}^{-1}$, respectively). These results sustain the conclusion that the primary cause of the early death of $H$. guilliermondii in mixed growth with $S$. cerevisiae is not ethanol or nutrient depletion (all cell-free supernatants were supplemented with nitrogen and yeast extract). Conversely to the results reported by Nissen et al. (2003), where the early death of $K$. thermotolerans and Torulospora delbrueckii in mixed cultures with $S$. cerevisiae suggested a cell-cell contactmediated mechanism, our results strongly indicate that some toxic compounds produced exclusively by $S$. cerevisiae are responsible for the early death of $H$. guilliermondii yeast.

It is well known that during wine fermentations yeasts can produce, besides ethanol, other toxic compounds, namely, killer toxins, short- and medium-chain fatty acids and sulphite, able to induce death of other yeasts - Saccharomyces spp. or nonSaccharomyces spp. (Schmitt and Breinig, 2002; Fleet, 2003). Several killer strains of $S$. cerevisiae, isolated from wine musts, have been found to kill other sensitive yeasts within the firsts days of fermentation, although the majority of these toxins are only effective against other S. cerevisiae strains (Shimizu, 1993; Pérez et al., 2001). To assure that classical killer toxins produced by $S$. cerevisiae were not involved in this early death phenomenon, killer activity of the three yeast strains used in the present work was tested against the classical killer toxins K1, $\mathrm{K} 2$, and K28 (at different $\mathrm{pH}$ ). Tests revealed that $\mathrm{S}$. cerevisiae CCMI 885 is killer-sensitive against the reference killer toxins (K1, K2 and K28) and H. guilliermondii NCYC 2380 as well as H. uvarum PYCC 4193T are killer neutral (Table 2 and Fig. 6). Additionally, none of the strains is killer positive towards the killer-sensitive strain EX33 (Table 2). Although significant, these results do not exclude however the production by $S$. cerevisiae of any other unknown killer-like toxins (e.g. peptides, proteins or glicoproteins) or even some fermentative metabolites potentially toxic for some non-Saccharomyces strains. To determine the nature of the toxic compounds involved in the early death of these non-Saccharomyces strains, as well as the death mechanism underlying this phenomenon, further investigation will be carried out.

\section{Acknowledgements}

The authors would like to thank Dr. J. C. Rivas for supplying yeast killer strain K28. The present work was supported by project POCTI/AGR/39974/2001, funded by Fundação para a Ciência e Tecnologia. Author F. Pérez-Nevado was beneficiary of a post-doc grant supported by Consejería de Educación, Ciencia y Tecnología (Junta de Extremadura, Spain) and European Social Fund.

\section{References}

Albergaria, H., Torrão, A.R., Hogg, T., Girio, F., 2003a. Physiological behaviour of Hanseniaspora guilliermondii under aerobic glucose-limited continuous cultures. FEMS Yeast Research 3, 211-216.

Albergaria, H., Torrão, A.R., Hogg, T., Girio, F., 2003b. The growth kinetics and fermentation behaviour of some non-Saccharomyces wine yeasts: Hanse- niaspora uvarum, H. guilliermondii and Candida stellata. 23rd ISSY, Budapest, Hungary.

Boone, C., Sdicu, A.M., Wagner, J., Degre, R., Sánchez, C., Bussey, H., 1990. Integration of the yeast K1 killer toxin gene into the genome of marked wine yeasts and its effect on vinification. American Journal of Enology and Viticulture 41, 37-42.

Chen, W.B., Han, Y.F., Jong, S.C., Chang, S.C., 2000. Isolation, purification, and characterization of a killer protein from Schwanniomyces occidentalis. Applied and Environmental Microbiology 66, 5348-5352.

Ciani, M., Fatichenti, F., 2001. Killer toxin of Kluyveromyces phaffii DBVPG 6076 as a biopreservative agent to control apiculate wine yeasts. Applied and Environmental Microbiology 67, 3058-3063.

Ciani, M., Ferraro, L., 1996. Enhanced glycerol content in wines made with immobilized Candida stellata cells. Applied and Environmental Microbiology 62, 128-132.

Ciani, M., Pepe, V., 2002. The influence of pre-fermentative practices on the dominance of inoculated yeast starter under industrial conditions. Journal of the Science of Food and Agriculture 82, 573-578.

Cocolin, L., Bisson, L.F., Mills, D.A., 2000. Direct profiling of the yeast dynamics in wine fermentations. FEMS Microbiology Letters 189, 81-87.

Constantí, M., Reguant, C., Poblet, M., Zamora, F., Mas, A., Guillamon, J.M., 1998. Molecular analysis of yeast population dynamics: effect of sulphur dioxide and inoculum on must fermentation. International Journal of Food Microbiology 41, 169-175.

Egli, C.M., Edinger, W.D., Mitrakul, C.M., Henick-Kling, T., 1998. Dynamics of indigenous and inoculated yeast populations and their effect on the sensory character of Riesling and Chardonnay wines. Journal of Applied Microbiology 85, 779-789.

Fleet, G.H., 2003. Yeast interactions and wine flavour. International Journal of Food Microbiology 86, 11-22.

Fleet, G.H., Heard, G.M., 1993. Yeasts: growth during fermentation. In: Fleet, G.H. (Ed.), Wine Microbiology and Biotechnology. Harwood Academic Publishers, Chur, Switzerland, pp. 27-54.

Ganga, M.A., Martínez, C., 2004. Effect of wine yeast monoculture practice on the biodiversity of non-Saccharomyces yeasts. Journal of Applied Microbiology 96, 76-83.

Granchi, L., Ganucci, D., Messini, A., Vincenzini, M., 2002. Oenological properties of Hanseniaspora osmophila and Kloeckera corticis from wines produced by spontaneous fermentations of normal and dried grapes. FEMS Yeast Research 2, 403-407.

Hansen, E.H., Nissen, P., Sommer, P., Nielsen, J.C., Arneborg, N., 2001. The effect of oxygen on the survival of non-Saccharomyces yeasts during mixed culture fermentations of grape juice with Saccharomyces cerevisiae. Journal of Applied Microbiology 91, 541-547.

Henick-Kling, T., Edinger, W., Daniel, P., Monk, P., 1998. Selective effects of sulfur dioxide and yeast starter culture addition on indigenous yeast populations and sensory characteristics of wine. Journal of Applied Microbiology 84, 865-876.

Ludovico, P., Sousa, M.J., Silva, M.T., Leao, C., Corte-Real, M., 2001. Saccharomyces cerevisiae commits to a programmed cell death process in response to acetic acid. Microbiology 147, 2409-2415.

Marquina, D., Santos, A., Peinado, J.M., 2002. Biology of killer yeasts. International Microbiology 5, 65-71.

Nissen, P., Arneborg, N., 2003. Characterization of early deaths of nonSaccharomyces yeasts in mixed cultures with Saccharomyces cerevisiae. Archives of Microbiology 180, 257-263.

Nissen, P., Nielsen, D., Arneborg, N., 2003. Viable Saccharomyces cerevisiae cells at high concentrations cause early growth arrest of non-Saccharomyces yeasts in mixed cultures by a cell-cell contact-mediated mechanism. Yeas 20, 331-341.

Pérez, F., Regodón, J.A., Valdés, M.E., De Miguel, C., Ramírez, M., 2000. Cycloheximide resistance as marker for monitoring yeasts in wine fermentations. Food Microbiology 17, 119-128.

Pérez, F., Ramírez, M., Regodón, J.A., 2001. Influence of killer strains of Saccharomyces cerevisiae on wine fermentation. Antonie van Leeuwenhoek 79, 393-399.

Pina, C., Santos, C., Couto, J.A., Hogg, T., 2004. Ethanol tolerance of five nonSaccharomyces wine yeasts in comparison with a strain of Saccharomyces 
cerevisiae — influence of different culture conditions. Food Microbiology $21,439-447$.

Pretorius, I.S., 2000. Tailoring wine yeast for the new millennium: novel approaches to the ancient art of winemaking. Yeast 16, 675-729.

Raspor, P., Cus, F., Jemec, K.P., Zagorc, T., Cadez, N., Nemanic, J., 2002. Yeast population dynamics in spontaneous and inoculated alcoholic fermentations of Zametovka must. Food Technology and Biotechnology 40, 95-102.

Regodón, J.A., Pérez, F., Valdés, M.E., De Miguel, C., Ramírez, M., 1997. A simple and effective procedure for selection of wine yeast strains. Food Microbiology 14, 247-254.

Rojas, V., Gil, J.V., Pinaga, F., Manzanares, P., 2003. Acetate ester formation in wine by mixed cultures in laboratory fermentations. International Journal of Food Microbiology 86, 181-188.

Romano, P., Suzzi, G., Comi, G., Zironi, R., Maifreni, M., 1997. Glycerol and other fermentation products of apiculate wine yeasts. Journal of Applied Microbiology 82, 615-618.
Schmitt, M.J., Breinig, F., 2002. The viral killer system in yeast: from molecular biology to application. FEMS Microbiology Review 26, 257-276.

Shimizu, K., 1993. Killer yeast. In: Fleet, G.H. (Ed.), Wine Microbiology and Biotechnology. Harwood Academic Publishers, Chur, Switzerland, pp. 243-263.

Vadasz, A.S., Jagganath, D.B., Pretorius, I.S., Gupthar, A.S., 2000. Electron microscopy of the K-2 killer effect of Saccharomyces cerevisiae T206 on a mesophilic wine yeast. Antonie van Leeuwenhoek International Journal of General and Molecular Microbiology 78, 117-122.

Woods, D.R., Bevan, E.A., 1968. Studies on the nature of the killer factor produced by Saccharomyces cerevisiae. Journal of General Microbiology $51,115-126$. 